\title{
PERLINDUNGAN HUKUM TERHADAP HAK KESEHATAN REPRODUKSI PEREMPUAN DARI KEKERASAN BERBASIS GENDER
}

\author{
Naimah \\ Dosen Fakultas Hukum Universitas Lumajang \\ E-mail: salsabila_ima@yahoo.co.id
}

\begin{abstract}
Solution of woman reproduction health is not new matter, but it still studied, because it still leave many problem for woman until today. National Commision of Anti Woman Violence (Komnas Perempuan) recorded that the number of woman violence is still high. According to the data from KPAI from 2011 until 2014, the number of woman violence is increase every year. Most of victim of physical violence are women. However, National Commission of Anti Woman Violence do the best to eliminate violation to woman. The curent law in Indonesia is still can not give the deterrent effect yet to the violence that happened to woman. added special laws on reproductive health only confirms CEDAW 1979, so not detailed yet according to the situation of indonesia society.

Solusi tentang kesehatan reproduksi perempuan adalah bukan perihal baru, tetapi masih tetap dipelajari, karena banyak menyisahkan permasalahan bagi perempuan sampai hari ini. Komisi Nasional Anti Kekerasan Terhadap Perempuan (Komnas Perempuan) mencatat tahun lau jumlah kekerasan terhadap perempuan sangat tinggi. Menurut data KPAI tahun 2011 hingga 2014, jumlah kasus kekrasan seksual selalu naik tahun demi tahun. Korban kekerasan fisik kebanyakkan adalah perempuan. Meskipun demikian, Komnas Perempuan bekerja keras berjuang untuk untuk menghilangkan kekerasan. Di Indonesia hukum saat ini belum dapat memberi efek jera atas kekerasan yang terjadi pada perempuan. yang ditambahkan hukum khusus tentang kesehatan reproduksi hanya mensahkan CEDAW 1979, sehingga belum yang terperinci menurut situasi ada Indonesia.
\end{abstract}

Keywords: kesehatan, reproduksi, perempuan, hak, hukum

Pembahasan tentang hak kesehatan reproduksi perempuan memang bukan hal yang baru, namun masih menarik untuk dibahas, sebab banyak menyisahkan masalah yang sampai hari ini terus terjadi terutama terhadap kaum perempuan, selain itu kesehatan reproduksi perempuan memegang peranan penting bagi keberlanjutan kehidupan manusia dari generasi ke generasi, sehingga terjaminnya keterwujudan kesehatan reproduksi merupakan keharusan bagi setiap Negara.

Pemikiran mengenai hak-hak reproduksi perempuan merupakan perkembangan dari konsep hak-hak asasi manusia, Masalah reproduksi sama sekali tidak dapat dilepaskan dari seksualitas dan tubuh manusia. Seksualitas tidak semata-mata dorongan naluri, atau kebutuhan biologis (khususnya alat kelamin), tetapi merupakan bentuk interaksi sosial atau bersifat relasional. Banyak perempuan yang tidak mengetahui haknya, karena dalam kehidupan perempuan masalah hak sangat langka dibicarakan.

Kesehatan reproduksi sebenarnya bukan hanya milik perempuan tetapi juga laki-laki namun, dalam setiap pembahasan kesehatan reproduksi baik secara tertulis maupun dalam forum ilmiah seperti seminar dan lain sebagainya, lebih banyak memfokuskan pembahasan 
kepada perempuan, hal tersebut dikarenakan banyak pelanggaran hak kesehatan reproduksi terjadi pada perempuan dari pada laki-laki.

Komisi Nasional Anti Kekerasan Terhadap Perempuan (Komnas Perempuan) mencatat selama 16 tahun terakhir angka kekerasan terhadap perempuan masih tinggi. Hal tersebut menjadi catatan khusus atas upaya berbagai pihak memberikan perlindungan terhadap perempuan.

Menurut data KPAI dari tahun 2011 hingga 2014, angka kasus kekerasan seksual selalu meningkat. Pada tahun 2011, kasus kekerasan sebanyak 328. Di tahun 2012 naik menjadi 746, lalu 525 kasus pada 2013 dan meningkat drastis sebanyak 1380 pada tahun 2014. Dari kasus kekerasan yang terjadi, dominasi korban kekerasan adalah perempuan dan anak. Menurut Mursyidah, kekerasan yang paling sering terjadi adalah pencabulan dan perkosaan. kasus kekerasan juga banyak terjadi oleh pasangan yang suka sama suka atau pacaran. Pelaku kekerasan biasanya adalah pacar sendiri, ini menyebabkan jumlah pengguguran bayi juga meningkat pertahunnya.

Menurut Khofifah Indar Parawansah, angka kematian ibu melahirkan di Indonesia masih sangat tinggi, bahkan mengalami peningkatan dari 228 per 100 ribu kelahiran di tahun 2012 saat ini naik menjadi 359 per 100 ribu kelahiran. Data Kemenkes menunjukkan ada sek itar 82 persen kematian karena melahirkan terjadi pada perempuan muda yang masih berusia kurang dari 15 tahun hingga usia 20 tahun.

Pendokumentasian Komnas Perempuan terhadap kasus kekerasan terhadap perempuan sepanjang 1998 - 2013 menunjukkan bahwa kasus kekerasan seksual berjumlah hampir seperempat dari seluruh total kasus kekerasan, atau 93.960 kasus dari seluruh kasus kekerasan terhadap perempuan yang dilaporkan (400.939). Dan itu sama artinya dengan 35 orang setiap harinya menjadi korban kekerasan seksual. Selain itu, sebagaimana dilaporkan dalam Catatan Tahunan (CATAHU) 2013 Komnas Perempuan, fakta kekerasan seksual menunjukkan bahwa kekerasan seksual terjadi dalam beragam kasus dengan intensitas dan variasi kekerasan yang semakin meningkat.

Selanjutnya Komnas perempuan juga menemukenali setidaknya terdapat 15 (lima belas) bentuk kekerasan seksual, yang belum seluruhnya tersedia payung hukum perlindungan bagi korban. Selain itu, peraturan perundang-undangan yang berlaku saat ini belum mengatur secara spesifik dan komprehensif tentang pencegahan, penanganan, pemulihan bagi korban, rehabilitasi pelaku, tanggung jawab negara serta pemidaaan akumulatif bagi pelaku kekerasan seksual.

Banyaknya kasus kekerasan seksual menjadikan banyak kalangan meragukan keterjaminnya hak kesehatan reproduksi di Indonesia, hal itu disebabkan banyak faktor diantaranya, ketidaktahuan masyarakat terutama kaum perempuan akan peraturan-peraturan yang melindungi hak-hak mereka yang berhubungan dengan kesehatan reproduksi.

Banyaknya kasus pelanggaran hak kesehatan reproduksi perempuan bukan berarti tidak ada upaya penanggulangannya serta tidak adanya gerakan untuk memperjuangkannya tetapi karena sulitnya kondisi yang melingkupinya dari berbagai aspek, hal ini sesuai pendapat Profesor Agnes Widanti bahwa Keberhasilan mempertahankan hak-hak perempuan bukanlah hal yang mudah, karena keterbatasan yang berkaitan dengan proses kerja dalam struktur Hukum menjadi masalah bagi feminis dalam memperjuangkan hak-hak perempuan.( Agnes Widanti. 2005).

Berdasarkan Latar Belakang di atas maka pembahasan tentang Perlindungan Hukum Terhadap Hak Kesehatan Reproduksi Perempuan Dari Kekerasan Berbasis Gender mempunyai rumusan masalah sebagai berikut:

1. Apakah yang dimaksud dengan hak kesehatan reproduksi Perempuan? 
2. Bagaimana perlindungan hukum terhadap hak kesehatan reproduksi perempuan dari kekerasan berbasis gender?

\section{Pembahasan}

\section{Perlindungan Hukum Terhadap Hak Kesehatan Reproduksi Perempuan Dari Kekerasan Berbasis Gender}

I. Hak-hak kesehatan reproduksi Perempuan

Menurut Igede Manuaba Masalah kesehatan reproduksi menjadi perhatian bersama dan bukan hanya individu yang bersangkutan, karena dampaknya luas menyangkut berbagai aspek kehidupan dan menjadi parameter kemampuan negara dalam menyelenggarakan pelayanan kesehatan terhadap masyarakat.( Mariana Amiruddin , 2003)

Pembahasan mengenahi Kesehatan Reproduksi sangat luas cakupannya karena mengandung beberapa aspek, bukan hanya masalah sakit atau kecatatan. Hal ini harus terlebih dahulu dipahami oleh perempuan sebelum lebih lanjut membahas hak-haknya yang berhubungan dengan kesehatan reproduksi.

Hak ialah Kewenangan yang melekat pada diri untuk melakukan atau tidak melakukan, memperoleh atau tidak memperolah sesuatu. Menurut Sudikno Merto Kusumo hak adalah kepentingan yang dilindungi hukum, sedangkan kepentingan adalah tuntutan perorangan atau kelompok yang diharapkan untuk untuk dipenuhi. Kepentingan pada hakikatnya mengandung kekuasaan yang dijamin dan dilindungi oleh hukum dalam melaksanakannya.(Sudikno Merto Kusumo, 2007 ) Sejalan dengan Sudikno, Alexandra juga mengatakan perlindungan hukum merupakan salah satu unsur yang harus ada dalam hak sehingga kepentingan terlindungi.

Pasal 1 ayat (1) Undang-Undang Nomor 36 Tahun 2009 Tentang Kesehatan menyebutkan Kesehatan adalah keadaan sehat, baik secara fisik, mental, spritual maupun sosial yang memungkinkan setiap orang untuk hidup produktif secara sosial dan ekonomis.

Kesehatan reproduksi ialah keadaan dimana terdapat kesejahteraan yang menyeluruh baik fisik, mental maupun sosial berkaitan dengan sistem, fungsi dan proses reproduksi. Pengertian sehat bukan hanya bebas dari penyakit atau bebas dari kecacatan, tetapi juga sehat secara mental serta sosial budaya.

Definisi di atas dapat disimpulkan bahwa kesehatan reproduksi mencakup tiga aspek yaitu sehat secara fisik, mental, dan sosial berkaitan dengan sistem, fungsi dan proses reproduksinya. Dalam hal ini perempuan mempunyai hak mendapatkan kesehatan baik secara fisik, mental maupun sosial, bukan hanya bebas dari rasa sakit secara fisik, tetapi juga bebas dari tekanan, paksaan dan diskriminasi.

Makna hak kesehatan reproduksi perempuan berdasarkan definisi di atas, berarti Kewenangan seseorang perempuan untuk melakukan atau tidak, memperoleh atau tidak memperoleh keadaan sehat, baik secara fisik, mental, spritual maupun sosial, berkaitan dengan sistem, fungsi dan proses reproduksinya. Dari definisi ini tidak ada paksaan dalam hak, karena seseorang dapat mempergunakan haknya atau mengabaikan hak yang dimiliki sepanjang tidak mengganggu hak orang lain, tetapi apabila seseorang apabila hak tersebut dilaksanakan, maka harus mendapat perlindungan hukum.

Tujuan umum program kesehatan reproduksi WHO adalah untuk memperkuat kapasitas negara untuk memungkinkan masyarakat untuk meningkatkan dan memproteksi kesehatannya dan pasangannya berkaitan dengan seksualitas dan reproduksi, dan mendapatkan akses dan menerima pelayanan kesehatan berkualitas saat memerlukan. (Khanna J (ed), 1997) 
Wujud atau indikator dari masing-masing aspek tersebut dalam kesehatan individu antara lain sebagai berikut :

1. Kesehatan fisik terwujud apabila seseorang tidak merasa sakit dan memang secara klinis tidak sakit. Semua organ tubuh normal dan berfungsi normal atau tidak gangguan fungsi tubuh.

2. Kesehatan mental (jiwa) mencakup tiga komponen, yakni : pikiran, emosional, dan spiritual.

Dalam hal hak kesehatan reproduksi, maka perempuan dalam hal ini berhak untuk menentukan sendiri hal-hal yang berhubungan dengan tubuhnya, misalnya memilih alat kontrasepsi apa yang akan digunakan. Emosi seorang perempuan juga harus diperhatikan dalam hal kesehatan reproduksi, misalnya kesiapan seorang perempuan untuk hamil tidak boleh dipaksakan, orang lain hanya bersifat memberi arahan dan motivasi bukan memaksa.

3. Kesehatan sosial terwujud apabila seseorang mampu berhubungan dengan orang lain secara baik, atau mampu berinteraksi dengan orang atau kelompok lain tanpa membeda-bedakan ras, suku, agama atau kepercayaan, status sosial, ekonomi, politik, dan sebagainya, saling menghargai dan toleransi.

Menurut sofwan mengenai kesehatan rohani dan sosial ; Kesehatan rohani diartikan sebagai kondisi yang memungkinkan perkembangan fisik, intelektual dan emosional yang optimal dari seseorang dan perkembangan iu sejalan selaras dengan keadaan orang-orang lain. Sedangkan pengertian sosial yaitu : perikehidupan di dalam masyarakat yang memungkinkan setiap warganya mempunyai cukup kemampuan untuk memelihara dan memjukan kehidupanya sendiri serta kehidupan keluarganya dan memungkikan mereka bekerja, beristirahat dan menikmati liburan. (Sofwan Dahlan, 2002) Hal ini didukung denga pendapat Hendric. L. Blum yang mengatakan bahwa faktor-faktor utama yang mempengaruhi kesehatan yaitu Lingkungan, Perilaku, pelayanan kesehatan dan Keturunan.

\section{Perlindungan hukum terhadap Hak kesehatan reproduksi Perempuan dari kekerasan berbasis Jender.}

Hak kesehatan reproduksi adalah perkembangan dari konsep hak asasi manusia. Hal senada juga dikatatan oleh prof. Agnes Widanti yang menyatakan bahwa hak reproduksi merupakan hak Asasi perempuan. Konsep Hak Asasi Manusia (HAM) menjamin hak wanita atas kedaulatan mental dan fisiknya, untuk bebas dari diskriminasi serta memperoleh tingkat kesehatan yang baik.

Salah satu hal yang harus ditegakkan dalam kehidupan bernegara adalah suatu kehidupan hukum dalam masyarakat. (Khudzaifah Dimati, 2010) Indonesia sebagai Negara hukum menjamin hak bagi setiap warga negarana termasuk perempuan.

Hak warga negara Indonesia atas pelayanan kesehatan dijamin dalam Undangundang Dasar Tahun 1945 pasal 28H bahwa setiap orang berhak mendapatkan lingkungan hidup yang baik dan sehat serta berhak memperoleh pelayanan kesehatan.

Hak atas sehatan reproduksi juga dijamin dalam Pasal 49 ayat (2) dan (3) Undang-undang Nomor 39 Tahun 1999 Tentang Hak Asazi Manusia (HAM) yang menyebutkan bahwa:

" (2) Wanita berhak untuk mendapatkan perlindungan khusus dalam pelaksanaan pekerjaan atau profesinya terhadap hal-hal yang dapat mengancam keselamatan dan atau kesehatannya berkenaan dengan fungsi reproduksi wanita." 
"(3) Hak khusus yang melekat pada diri wanita dikarenakan fungsi reproduksinya, dijamin dan dilindungi oleh hukum."

Hak atas pelayanan kesehatan dan jaminan sosial sesuai dengan kebutuan fisik, mental, spiritual, dan sosial dijamin dalam Pasal 8 Undang-undang Nomor 23 Tahun 2002 Tentang Perlinduang Anak.

Pasal 5 Undang-undamg Nomor 23 tahun 2004 tentang Penghapusan Kekerasan dalam Rumah Tangga (PKDRT) yang menyebutkan bahwa :Setiap orang dilarang melakukan kekerasan dalam rumah tangga terhadap orang dalam lingkup rumah tangganya, dengan cara:

a. Kekerasan fisik;

b. Kekerasan Psikis;

c. Kekerasan seksual; atau

d. Penelantaran Rumah Tangga.

Undang-undang Nomor 36 Tahun 2009 tentang kesehatan Pasal 4 menyebutkan "setiap orang berhak atas Kesehatan" selanjutnya dalam Pasal 5 menyebutkan "Setiap orang mempunyai hak yang sama dalam memperoleh akses atas sumber daya di bidang kesehatan" Setiap orang berarti tidak memperhatikan jenis kelamin oleh karena itu tidak boleh ada perbedaan antara laki-laki dan perempuan secara umum.

Peraturan khusus dan terinci tentang kesehatan reproduksi memang belum diatur di Indonesia tetapi Undang-undang Nomor 36 Tahun 2009 tentang kesehatan, Undangundang Nomor 39 Tahun 1999 Tentang Hak Asazi Manusia (HAM) dan Undang-undang Nomor 23 Tahun 2002 Tentang Perlinduang Anak serta Undang-undamg Nomor 23 tahun 2004 tentang Penghapusan Kekerasan dalam Rumah Tangga (PKDRT)dalam pasal-pasalnya telah mengatur masalah kesehatan reproduksi secara umum.

Meskipun belum diatur secara khusus dan terperinci namun Pemenuhan hak pelayanan kesehatan reproduksi perempuan telah dijamin dalam konvensi penghapusan segala bentuk diskriminasi terhadap perempuan tahun 1979, yang diratifikasi oleh Indonesia, dengan Undang-undang Nomor 7 Tahun 1984 Tentang Pengesahan Konvensi Mengenai Penghapusan Segala Bentuk Diskriminasi Terhadap Wanita (Convention On The Elimination Of All Forms Of Discrimination Against Women (CEDAW)).

Dalam pasal 12 dari CEDAW (Convention On The Elimination Of All Forms Of Discrimination Against Women) 1979 disebutkan :

1. Negara-negara peserta wajib membuat peraturan-peraturan yang tepat untuk menghapus diskriminasi terhadap wanita dibidang pemeliharaan kesehatan dan supaya menjamin diperolehnya pelayanan kesehatan termasuk pelayanan yang berhubungan dengan keluarga berencana, atas dasar persamaan antara pria dan wanita.

2. Negara-negra peserta wajib menjamin kepada wanita pelayanan yang layak untuk perempuan dalam hubungannya dengan kehamilan, persalinan dan periode pasca persalinan, Apabila perlu menyediakan pelayanan gratis, serta pemberian makanan bergizi yang cukup selama kehamilan dan masa menyusui.

Ketentuan diratifikasinya CEDAW 1979 dengan Undang-undang Nomor 7 Tahun 1984 tersebut, menjamin hak bagi wanita di negara Indonesia untuk mendapatkan pelayanan kesehatan khususnya pelayanan kesehatan reproduksi tanpa adanya diskriminasi. Ketentuan ini menjamin hak perempuan atas kesehatan reproduksinya, agar terlindungi dari berbagai bentuk pelanggaran termasuk kekerasan berbasis jender. Seperti pemerkosaan, pemaksaan alat kontrasepsi tertentu, pemaksaan aborsi, termasuk pemaksaan 
terapi kehamilan sebab tidak sedikit pasangan yang belum mempunyai keturunan memaksa seorang peempun untuk melakukan terapi tertentu tanpa melakukan tes terlebih dahulu penyebab tidak atau keterlambatan memperoleh keturunan.

Kesepakatan dalam konferensi internasional kependudukan dan pembangunan di Cairo tahun 1994, menyebutkan hak-hak reproduksi meliputi:

1) Hak mendapat informasi dan pendidikan kesehatan reproduksi;

2) Hak mendapat pelayanan dan perlindungan kesehatan reproduksi;

3) Hak untuk kebebasan berpikir dan membuat keputusan tentang kesehatan reproduksinya;

4) Hak untuk memutuskan jumlah dan jarak kelahiran anak;

5) Hak untuk hidup dan terbebas dari resiko kematian karena kehamilan, kelahiran atau masalah jender

6) Hak atas kebebasan dan keamanan dalam pelayanan kesehatan reproduksi;

7) Hak untuk bebas dari penganiayaan dan perlakuan buruk yang menyangkut kesehatan reproduksi;

8) Hak mendapatkan manfaat dari hasil kemajuan ilmu pengetahuan di bidang kesehatan reproduksi;

9) Hak atas kerahasiaan pribadi dalam menjalankan kehidupan reproduksinya;

10) Hak untuk membangun dan merencanakan keluarga,

11) Hak atas kebebasan berkumpul dan berpartisipasi dalam politik yang bernuansa kesehatan reproduksi,

12) Hak atas kebebasan dari segala bentuk diskriminasi dalam kesehatan reproduksi.

Hak berkaitan erat dengan kewajiban, maka membahas hak kesehatan reproduksi perempuan akan lebih lengkap apabila juga membahas kewajiban memenuhinya. Berdasarkan Undang-undang Nomor 36 Tahun 2009 tentang kesehatan, yang mempunyai kewajiban untuk menjaga dan memelihara kesehatan reproduksi perempuan sebagai berikut :

a. Perempuan itu sendiri

b. Keluarga

c. Masyarakat, dalam Pasal 9 Undang-Undang Nomor 36 Tahun 2009

d. Pemerintah, berdasarkan Pasal 14 " Pemerintah bertanggung jawab merencanakan, mengatur, menyelenggarakan, membina, dan mengawasi penyelenggaraan upaya kesehatan yang merata dan terjangkau oleh masyarakat" Upaya kesehatan dalam pasal ini tentunya termasuk upaya kesehatan reproduksi bagi perempuan. Sebagaimana disebutkan dalam pasal 48 ayat 1 poin (e) Undang-undang Kesehatan bahwa Penyelenggaraan upaya kesehatan salah satunya adalah kesehatan reproduksi.

Kewajiban pemerintah juga terdapat dalam hasil Konferensi International tentang kependudukan dan pembangunan (International Conference on Population and Development- ICPD) di kairo tahun 1994, yang terdiri atas sepuluh program kesehatan reproduksi, berupa kesehatan primer yang harus diperhatikan oleh semua negara, termasuk Indonesia, yaitu :

1. Pelayanan sebelum, semasa kehamilan dan pasca kehamilan;

2. Pelayanan kemandulan;

Pelayanan ini seharusnya berlaku kepada laki-laki dan perempuan karena kemandulan bisa saja dari pihak suami maupun istri. Masyarakat Indonesia sebagian besar masih mempunyai paradikma bias Jender apabila berkaitan dengan kemandulan, karena dalam pikiran mereka apabila suami 
istri tidak dapat memiliki keturunan maka penyebabnya adalah perempuan (Istri) padahal penyebabnya bisa saja suami yang mengalami kemandulan.

3. Pelayanan Keluarga Berencana (KB) yang optimal;

Pelayanan keluarga berencana dalam prakteknya di Indonesia juga bias jender, hal ini dapat dilihat dalam setiap sosialisasi dan penyuluhan yang berhubungan dengan keluarga berencana, sebagian besar pesertanya adalah ibu-ibu, padahal suami juga harus tahu informasi tentang keluarga berencana, selain itu salah satu metode kontrasepsi ada yang dilakukan oleh suami (laki-laki), hal ini seakan mengkondisikan bahwa perempuanlah yang harus melakukan kontrasepsi.

4. Pelayanan dan penyuluhan HIV/AIDS;

5. Pelayanan Aborsi;

6. Pelayanan dan pemberian Komunikasi, Informasi dan Edukasi (KIE) yang berkaitan dengan kesehatan reproduksi;

7. Pelayanan kesehatan seksual dan reproduksi remaja;

8. Tanggungjawab keluarga;

9. Peniadaan sunat dan mutilasi anak perempuan dan

10. Pelayanan kesehatan lansia.

7 Aksi Dalam Millenium Project Task Force in Education And Gender Equility

1. Memperkuat akses anak perempuan untuk mendapat pendidikan dasar sembilan tahun;

2. Menjamin hak-hak dasar reproduksi dan seksual perempuan;

3. Membangun infrastruktur untuk mengurangi beban kerja perempuan dan anak perempuan;

4. Menjamin hak waris dan hak kepemilikan properti perempuan dan anak perempuan (zoz);

5. Menjamin tak ada diskriminasi terhadap perempuan dalam pekerjaan;

6. Menjamin keterwakilan perempuan dalam parlemen dan pemerintah daerah;

7. Meningkatkan upaya penghapusan kekerasann terhadap perempuan dan anak perempuan.

\section{Penutup}

\section{A. Simpulan}

1. Hak kesehatan reproduksi Perempuan, berarti Kewenangan seseorang perempuan untuk melakukan atau tidak, memperoleh atau tidak memperoleh keadaan sehat, baik secara fisik, mental, spritual maupun sosial, berkaitan dengan sistem, fungsi dan proses reproduksinya. Dari definisi ini tidak ada paksaan dalam hak, karena seseorang dapat mempergunakan haknya atau mengabaikan hak yang dimiliki sepanjang tidak mengganggu hak orang lain, tetapi apabila seseorang apabila hak tersebut dilaksanakan, maka harus mendapat perlindungan hukum.

2. Perlindungan hukum terhadap Hak kesehatan reproduksi Perempuan dari kekerasan berbasis jender dapat dikelompokkan menjadi dua yaitu:

1) Hak kesehatan reproduksi Perempuan secara umum dijamin dalam ketentuan undang-undang yaitu:

a) Undang-undang Dasar Tahun 1945 pasal 28H bahwa: "setiap orang berhak mendapatkan lingkungan hidup yang baik dan sehat serta berhak memperoleh pelayanan kesehatan"

b) Undang-undang Nomor 39 Tahun 1999 Tentang Hak Asazi Manusia (HAM) yang menyebutkan bahwa: 
"(2) Wanita berhak untuk mendapatkan perlindungan khusus dalam pelaksanaan pekerjaan atau profesinya terhadap hal-hal yang dapat mengancam keselamatan dan atau kesehatannya berkenaan dengan fungsi reproduksi wanita."

"(3) Hak khusus yang melekat pada diri wanita dikarenakan fungsi reproduksinya, dijamin dan dilindungi oleh hukum."

c) Undang-undang Nomor 23 Tahun 2002 Tentang Perlinduang Anak

d) Undang-undang Nomor 36 Tahun 2009 tentang kesehatan

Pasal 4:

"setiap orang berhak atas Kesehatan"

Pasal 5

"Setiap orang mempunyai hak yang sama dalam memperoleh akses atas sumber daya di bidang kesehatan"

e) Pasal 5 Undang-undamg Nomor 23 tahun 2004 tentang Penghapusan Kekerasan dalam Rumah Tangga (PKDRT) yang menyebutkan bahwa :

Setiap orang dilarang melakukan kekerasan dalam rumah tangga terhadap orang dalam lingkup rumah tangganya, dengan cara:

a. Kekerasan fisik;

b. Kekerasan Psikis;

c. Kekerasan seksual; atau

d. Penelantaran Rumah Tangga.

2) Hak kesehatan reproduksi Perempuan secara Khusus:

Meskipun belum diatur secara khusus dan terperinci namun Pemenuhan hak pelayanan kesehatan reproduksi perempuan telah dijamin dalam konvensi penghapusan segala bentuk diskriminasi terhadap perempuan tahun 1979, yang diratifikasi oleh Indonesia, dengan Undang-undang Nomor 7 Tahun 1984 Tentang Pengesahan Konvensi Mengenai Penghapusan Segala Bentuk Diskriminasi Terhadap Wanita (Convention On The Elimination Of All Forms Of Discrimination Against Women (CEDAW)). 
B. Saran

1. Bagi Pemerintah agar membuat undang-undang khusus kesehatan reproduksi beserta peraturan pelaksananya bukan hanya meratifikasi hasil CEDAW (Convention On The Elimination Of All Forms Of Discrimination Against Women) 1979. Sebab dengan membuat aturan sendiri dapat disesuaikan dengan kondisi masyarakat Indonesia., sehingga lebih tepat kepada sasaran dan tujuan yang dimaksudkan oleh undang-undang.

2. Bagi perempuan harus lebih rajin menggali informasi tentang hak kesehatan reproduksinya sehingga tidak mudah untuk dijadikan sasaran pelanggaran hak kesehatan reproduksi dan kekerasan berbasis jender.

\section{Daftar Pustaka}

Agnes Widanti, Hukum Kependudukan dan Reproduksi, Makalah disampaikan pada perkuliahan Magister Hukum Kesehatan Unika Soegijapranata, Semarang: 2009, tidak dipublikasikan.

Agnes Widanti. 2005. Hukum Berkeadilan Jender (Aksi-Interaksi Kelompok Buruh Perempuan dalam Perubahan Sosial. Jakarta: Kompas.

Alexandra Indriyanti Dewi, Etika dan Hukum Kesehatan, Yogyakarta: Pustaka Book Publisher, 2008.

Departemen Kesehatan R.I, Pedoman Untuk Tenaga Kesehatan Usaha Kesehatan Sekolah di Tingkat Sekolah Lanjutan, Direktorat Jenderal Bina Kesehatan Masyarakat Direktorat bina Kesehatan Anak, 2007.

Badan Koordinasi Keluarga Berencana Nasional Propinsi Jawa Timur, Pedoman Pengelolaan Program Kesehatan Reproduksi Remaja di Jawa Timur, Surabaya: 2002.

Khanna J (ed), Advancing Reproductive Health Trough: The Role Of The Special Programme Progess In Human Reproduction Research No 42, WHO, Genewa: 1997.

Khudzaifah Dimati, 2010. Teorisasi Hukum Studi tentang perkembangan pemikiran Hukum di Indonesia 1945-1990. Yogyakarta: Genta Publishing.

Mariana Amiruddin, Kesehatan dan Hak Reproduksi Perempuan Panduan untuk Jurnalis, Yayasan Jurnal Perempuan (YJP) dan the Japan Foundation, Jakarta: 2003.

Soekidjo Notoatmojo, Pendidikan dan Perilaku Kesehatan, Jakarta: Rineka Cipta, 2003.

Sofwan Dahlan, Hukum Kesehatan, Semarang: Undip, 2002.

Sulistyowati Irianto, Perempuan dan Hukum : Menuju Hukum Yang Berperspektif Kesetaraan dan Keadilan, Jakarta: Yayasan Obor Indonesia, 2006.

Sudikno Merto Kusumo, Mengenal Hukum Suatu Pengantar, Yogyakarta: Liberti, 2005.

Perundang-undangan 
Undang-undang Dasar Tahun 1945

Undang-undang Nomor 39 Tahun 1999 Tentang Hak Asazi Manusia (HAM) Undang-undang Nomor 23 Tahun 2002 Tentang Perlinduang Anak

Undang-undang Nomor 36 Tahun 2009 tentang kesehatan

Undang-undamg Nomor 23 tahun 2004 tentang Penghapusan Kekerasan dalam Rumah Tangga (PKDRT).

Undang-undang Nomor 7 Tahun 1984 Tentang Pengesahan Konvensi Mengenai Penghapusan Segala Bentuk Diskriminasi Terhadap Wanita (Convention On The Elimination Of All Forms Of Discrimination Against Women (CEDAW)).

Konvensi penghapusan segala bentuk diskriminasi terhadap perempuan tahun 1979

Hasil Konferensi International tentang kependudukan dan pembangunan (International Conference on Population and Development- ICPD) di kairo tahun 1994

http://www.oocities.org/guntoroutamadi/artikel-hakreproduksi.html

https://setyakarioriansyah.wordpress.com

http://www.cnnindonesia.com/nasional/20141015144255-20-6486/kekerasan-terhadapperempuan-masih-tinggi/

http://www.beritasatu.com/megapolitan/298569-jumlah-kasus-kekerasan-terhadapperempuan-dan-anak-terus-meningkat.html

Metrotvnews.com. sabtu 21 Pebruari 2015.

http://www.komnasperempuan.or.id/2015/09/14930/

http://www.komnasperempuan.or.id/2015/09/14930/ 